\title{
NIDA's Funding Policies Contribute to Racial Biases in the Treatment of Drug Use
}

\author{
$\underline{\text { Priyanka N. Bushana }}^{1,2}$, Emma N. Cook ${ }^{3,4}$ \\ ${ }^{1}$ Washington State University Health Sciences, Biomedical Sciences Department, Spokane WA \\ ${ }^{2}$ Washington State University Health Sciences, Health Sciences Student Advocacy Association, Spokane, WA \\ ${ }^{3}$ University of Virginia, Department of Chemistry, Charlottesville, VA \\ ${ }^{4}$ University of Virginia, The Science Policy Initiative at UVA, Charlottesville, VA \\ https://doi.org/10.38126/ISPG190102 \\ Corresponding author: privanka.bushana@gmail.com
}

Keywords: NIDA; drug policy; addiction; drug abuse; racial inequities; research funding; Ginther gap

Executive Summary: The research funding policies of the National Institute on Drug Abuse (NIDA) reinforce racial biases by stigmatizing drug use. NIDA is currently working toward "eliminating racism in [its] workplace, scientific workforce, and research portfolio" via its Racial Equity Initiative (REI) (Volkow 2021; National Institute on Drug Abuse 2021d). However, the REI falls short of committing to a sustainable or direct course of action to reform its funding policies. This policy memo offers NIDA guidance to prioritize the REI's Actionable Steps to address racial stigmas underlying its current funding policies by: 1) closing the Ginther gap, 2) increasing research into the social determinants of health and equity (SDOH/E) underlying drug use, and 3) increasing research into normative drug use.

\section{Introduction}

i. The National Institute on Drug Abuse's (NIDA) research funding policies intensify racial biases by creating stigmas in drug use and the treatment of addiction.

NIDA is the primary funding source for drug use and addiction research in the U.S. with the goals of: 1) understanding the causes and consequences of drug use and addiction, 2) developing strategies to prevent drug use and its consequences, 3) developing improved treatments for substance use disorders, and 4) increasing NIDA's public health impact (National Institute on Drug Abuse 2016). However, these goals are impeded by the biases in NIDA's funding strategies. NIDA-funded research reinforces stigmas surrounding drug use which are disproportionately weaponized against Black communities due to systemic racism and pre-existing racial disparities inherent in institutions such as law enforcement and healthcare (The Drug Policy Alliance 2021b, 2021e; Atkins, Dopp, and Temaner 2020). ii. NIDA-funded research promotes expectations that all drug use will have negative consequences, leading to a publication bias that favors results emphasizing the negative effects of drug use (Hart et al. 2012). These biases can be traced back to NIDA's foundational funding in the 1970s, during the War on Drugs. A correlation between crime and drug use was established by NIDA's first director, Dr. Robert DuPont, whose seminal study in the Washington, D.C. jail linked the heroin epidemic to a steep rise in serious crime (Cooper 2015; DuPont 1971, 2009). This work set a precedent that correlated drug use and incarceration without acknowledging the higher rates of arrest faced by communities of color (The Drug Policy Alliance 2021e). Roughly 80\% of people in federal prison for drug-related offenses are Black or Latino, despite similar rates of drug-related offenses in White communities (Rosenberg, Groves, and Blankenship 2017; Tonry 1994; Garland and Bumphus 2012; Volkow 2021; The Drug Policy Alliance 2021e). 
Further, these crimes are largely non-violent, despite the expectations established by DuPont's D.C. jail study (The Drug Policy Alliance 2021a). NIDA's early administrators conflated drug use with criminality and moral failings by repeatedly claiming that "drug use is not only a moral outrage but a nasty, unpleasant problem as well [due to] the crime it spawns" (Goodwin 1988). In the context of the disproportionate sentencing, arrests, and convictions of Black and Latino populations, NIDA's moral judgements conflating criminality and drug use made it appear that minority populations were more prone to drug use, helping to establish racial stereotypes (The Drug Policy Alliance 2021c).

Such messaging from the scientific institution, which is the authority on drug use research in the United States produces a culture that devalues and dehumanizes drug users.

iii. NIDA's current funding prioritizes finding the problems that comprise addiction over developing solutions for its prevention and treatment.

In pursuit of treatment options that would disrupt criminal behavior and addiction, in the 1990s, NIDA shifted its research focus to understanding the neurobiology that motivates drug use (DuPont 2009). This is demonstrated by the breakdown of NIDA's research portfolio, which allocates a third of its budget to neuroscience. While it is critical to understanding and addressing drug use, NIDA's overemphasis on neurobiology undermines the importance of systemic factors influencing drug use, as described by the social determinants of health and equity (SDOH/E) (Walker and Netherland 2019; Krane 2019). SDOH/E describe the conditions that inform individuals' health and quality-of-life outcomes and risks. SDOH/E can have a profound influence on individuals' exposure to and continued use of drugs. This is exemplified by the increased frequency with which injection drug users seek emergency medical services due to unstable housing and poor access to healthcare (Palepu et al. 1999; Becker and Newsom 2003). Further, research shows that housing instability often precedes initial drug use, perpetuating a vicious cycle and establishing the importance of addressing the SDOH/E in effectively reducing drug use (Aidala et al. 2005; Cheng et al. 2014). iv. NIDA's Racial Equity Initiative (REI) aims to correct racial biases perpetuated by its research portfolio, largely by focusing on SDOH/E.

In the wake of the murder of George Floyd in May 2020, NIDA established the REI to encourage examination of the impact of racial disparities on drug use and addiction (Volkow 2021; National Institute on Drug Abuse 2021d). While commendable, the REI's current progress consists of a list of "Actionable Steps," which are not yet prioritized and lack structure for implementation.

We propose immediate implementation of the following policy options for NIDA to pursue the REI's actionable steps:

- Increase funding availability for Black primary investigators (PIs) by biasing discretionary funding decisions in their favor, increased Black representation on Special Emphasis Panels (SEPs) formed for grant peer review, and transparent reporting on the demographics of both pools of PIs (grant awardees and SEP members).

- Increase opportunities to study SDOH/E which impact drug use and inclusion of $\mathrm{SDOH} /$ E metrics in longitudinal studies.

- Increase opportunities to study the effects of normative drug use and inclusion of normative drug use metrics in longitudinal studies. This option is not included in the REI's Actionable Steps but can build on its momentum.

\section{Policy Options}

\section{i. Policy Option 1: Address the Ginther Gap}

A 2011 report on NIH funding rates revealed a significant racial gap in distributed awards. Despite decades of reports on racial disparities in drug use and addiction, NIDA continues to face criticism for prioritizing funding for a small cadre of White researchers (Booth 1988; Shikles et al. 1990). Black PIs remain 8\% less likely than White PIs to be awarded funding; this disparity has come to be known as the Ginther gap (Ginther et al. 2011; Taffe and Gilpin 2021). Despite the NIH and NIDA's laudable efforts to address the Ginther gap when it was discovered, there has been negligible progress 
in the intervening years (National Institutes of Health 2021).

Thus, a multi-pronged approach will be necessary to close the gap (as proposed by Taffe and Gilpin, 2021). We propose that NIDA:

- Increase the representation of Black reviewers on grant review SEPs to reflect the demographics of all Americans. As of 2015, only $2.4 \%$ of NIH study section members were Black, as compared to $14 \%$ of US citizens (Hoppe et al. 2019).

- Revise discretionary funding decisions to prioritize topics commonly proposed by Black PIs. As it stands, discretionary decisions to fund grants that fall below the payline prioritize White PIs. In 2019, all 119 discretionary awards went to White PIs, totaling almost half of the number of funded Black PIs (Hoppe et al. 2019).

- Transparently report statistics on race and ethnicity for SEPs and at each stage of NIDA's R01 application and review processes.

Because communities of color suffer the negative effects of drug use and related policies, it is important to consider perspectives of minority researchers as stakeholders. A recent study indicated that a major contributor to the Ginther gap is reviewers' deprioritization of research topics commonly proposed by Black PIs (Mervis 2019). Prioritizing these topics is likely to promote novel community-based approaches, which could advance NIDA's goals to develop strategies for substance abuse prevention, treatment, and recovery (Goals 2 \& 3) (National Institute on Drug Abuse 2016). NIDA's REI also identified increasing funding for community-based research and changing the scientific review process as Actionable Steps. Both Actionable Steps will reinforce emphasis on SDOH/E in its research portfolio and address structural racism in NIDA's work (National Institute on Drug Abuse 2021b).

ii. Policy Option 2: Shift Funding to Focus on SDOH/E As acknowledged by recent executive summaries from the REI, SDOH/E are largely unacknowledged in NIDA's current research portfolio (National Institute on Drug Abuse 2021b). A shift in NIDA's focus to the SDOH/E that underlie drug abuse will expand our understanding of social factors that promote exposure to, and continual use of, illicit drugs. We suggest the following approaches:

- Incorporate collection and analysis of SDOH/E data into existing NIDA-funded longitudinal studies. For example, the Adolescent Brain Cognitive Development longitudinal study aims to understand factors underlying adolescents' propensity to use drugs. This study should be modified to include data on the SDOH/E such as employment status, housing, and interactions with police (Hart 2017; National Institute on Drug Abuse 2021a).

- Use discretionary funding decisions to prioritize grant applications focused on community-based approaches that address SDOH/E related to drug use (see Policy Option 1). Black PIs are more likely to propose community-based and harm reduction studies, a strategy that has yet to be studied by NIDA but is effective in ten countries (Mervis 2019; The Drug Policy Alliance 2021d).

- Increase the number of funding opportunities focused on addressing $\mathrm{SDOH} / \mathrm{E}$ related to drug use. NIDA is currently sponsoring an RFP focused on the social and environmental risk factors for populations most affected by drug use (National Institute on Drug Abuse 2021e). We suggest expansion of this type of focused research to other NIDA funding mechanisms as well.

Emphasis on the SDOH/E will drive NIDA's development of treatments for substance abuse disorders and help drug users maintain meaningful and sustained recovery (Goal 3) (National Institute on Drug Abuse 2016). Increasing community-based research strategies and expanding capture of $\mathrm{SDOH} / \mathrm{E}$ in national datasets are also strategies identified as Actionable Steps by NIDA's REI. As mentioned in the REI Executive Summary, a "big data" approach to SDOH/E allows NIDA to identify opportunities for intervention without fear of further stigmatizing drug users (National Institute on Drug Abuse 2021b). 
iii. Policy Option 3: Increase Research into Normative Drug Use

Addiction research in the U.S. is founded on the underlying belief that the addictive and harmful qualities of illicit drugs are inescapable (Hart 2020). Further, the focus on the neurobiology of addiction produces a culture that sees any drug use as pathological (Hart 2017). But the fact remains, only a minority (10-30\%) of people who consume illicit drugs will ever become addicted to them (Volkow, Koob, and McLellan 2016; Hart 2020).

NIDA-funded research largely avoids studying this majority of individuals who consume drugs but do not become addicted to them. Neglecting the study of non-addicted individuals constrains our ability to understand the factors that promote or prevent the conversion of normative (i.e. self-regulated or recreational) drug use to problematic drug use. Research into normative drug use could uncover individuals' initial motivations for drug use, ability to self-regulate, and resilience as it relates to the ability to stop drug use (Walker and Netherland 2019). We suggest that NIDA:

- Create funding opportunities to focus on the study of normative drug use within each of its research divisions. This will provide an understanding of how normative drug use informs prevention, behavioral, and therapeutic research.

- Incorporate assessments of normative drug use into current longitudinal studies and extramural research.

Studying normative drug use is likely to result in an understanding of the biological, environmental, behavioral, and social causes and consequences of drug use as well as ways to prevent drug use (Goals $1 \& 2$ ) (National Institute on Drug Abuse 2016). This type of research will require careful framing; if presented incorrectly, findings on normative drug use could be seen as endorsements for the use of drugs. Research on normative drug use is not acknowledged in the REI but should be included in the initiative. NIDA has historically produced biased research by ignoring the majority of drug users, and these biases cannot be corrected without including normative drug use.

\section{Policy Recommendation}

We recommend NIDA focus the weight of its REI on first addressing the Ginther gap and the lack of current SDOH/E research (Policy Options $1 \& 2$ 2). These changes synergize well and are already supported by several Actionable Steps listed in the REI summary documentation (National Institute on Drug Abuse 2021b). We believe that these changes alone will have a profound impact on downstream stigmas that lead to racial inequities in the treatment of addiction. These policy changes will pave the way to normalizing conversations around addiction and drug use and provide a framework for research into normative drug use (Policy Option 3). This Policy Option is not included in the REI plan; however, we believe that studying normative drug use has the greatest potential to de-stigmatize and improve treatment of individuals by downstream institutions like law enforcement $\&$ healthcare.

\section{i. Disadvantages}

Overall, these options will take careful and dedicated work by NIDA administrators and researchers who will need to rewrite RFAs, adjust funding mechanisms, and redistribute committees. This might disrupt the existing addiction research community, especially destabilizing the funding of established researchers who may find that they need to develop new collaborations or use new methodologies to access previously available funding pools. However, these changes could promote greater collaboration between affected communities and researchers, promising more informed and responsive work from NIDA in the future.

\section{ii. Advantages}

Following the George Floyd uprisings of 2020, NIH and NIDA separately launched initiatives aimed at confronting systemic and structural racism in the scientific work and infrastructure that they support (Volkow 2021; Collins 2021). In light of the momentum and funding allocated to the REI, the policy options laid out here are timely and politically feasible. Additionally, these options do not necessarily require new funding, as NIDA's REI allocates funds to address the proposed policy options. Further, these policy options do not require novel funding mechanisms or technologies to 
support their development. While redefining the distribution of NIDA's research funding may create some growing pains, we believe that the shift in focus will address inequities experienced by Black and minority communities as a result of the stigmatization of drug use and addiction. Current methods of addressing drug abuse and addiction have not changed trends in drug use or drug-related deaths (National Institute on Drug Abuse 2021c).

\section{References}

Aidala, Angela, Jay E Cross, Ron Stall, David Harre, and Esther Sumartojo. 2005. "Housing status and HIV risk behaviors: implications for prevention and policy." AIDS and Behavior 9 (3): 251-265. https:/pubmed.ncbi.nlm.nih.gov/16088369/.

Atkins, Jennifer, Anna Legreid Dopp, and Edna Boone Temaner. 2020. "Combatting the Stigma of Addiction-The Need for a Comprehensive Health System Approach." NAM Perspectives. https://nam.edu/combatting-the-stigma-of-addic tion-the-need-for-a-comprehensive-health-syste m-approach/.

Becker, Gay, and Edwina Newsom. 2003. "Socioeconomic status and dissatisfaction with health care among chronically ill African Americans." American journal of public health 93 (5): 742-748. https://www.ncbi.nlm.nih.gov/pmc/articles/PM C1447830/.

Booth, William. 1988. "War breaks out over drug research agency." Science 241 (4866): 648. https://pubmed.ncbi.nlm.nih.gov/2840741/.

Cheng, Tessa, Evan Wood, Paul Nguyen, Thomas Kerr, and Kora DeBeck. 2014. "Increases and decreases in drug use attributed to housing status among street-involved youth in a Canadian setting." Harm reduction journal 11 (1): 1-6. https://harmreductionjournal.biomedcentral.co m/articles/10.1186/1477-7517-11-12.

Collins, Francis. 2021. "NIH stands against structural racism in biomedical research." March 1, 2021. https://www.nih.gov/about-nih/who-we-are/nih -director/statements/nih-stands-against-structur al-racism-biomedical-research.

Cooper, Hannah LF. 2015. "War on drugs policing and police brutality." Substance use \& misuse 50 (8-9):

1188-1194. https://www.ncbi.nlm.nih.gov/pmc/articles/PM C4800748/.
The proposed policy options provide a direct route for implementation of the Actionable Steps outlined in NIDA's REI, further supporting the feasibility and momentum towards implementing these options. We believe that these policy changes will increase the public health impact of NIDA's research and programs (Goal 4) (National Institute on Drug Abuse 2016).

DuPont, Robert. 1971. "Profile of a heroin-addiction epidemic." The New England Journal of Medicine 285 (6): 320-324. https://doi.org/10.1056/NEJM19710805285060 5. https://pubmed.ncbi.nlm.nih.gov/5091324/.

DuPont, Robert. 2009. "Reflections on the early history of National Institute on Drug Abuse (NIDA): implications for today." Journal of Drug Issues 39 (1):

5-14. https://journals.sagepub.com/doi/abs/10.1177/ 002204260903900101.

Garland, Tammy S, and Vic W Bumphus. 2012. "Race, bias, and attitudes toward drug control policy." Journal of Ethnicity in Criminal Justice 10 (2): 148-161. http://ascdwc.com/wp-content/uploads/2013/0 2/garland 1.pdf.

Ginther, Donna K, Walter T Schaffer, Joshua Schnell, Beth Masimore, Faye Liu, Laurel L Haak, and Raynard Kington. 2011. "Race, ethnicity, and NIH research awards." Science 333 (6045): 1015-1019. https://science.sciencemag.org/content/333/60 $\underline{45 / 1015}$.

Goodwin, Frederick K. 1988. "NIDA's Role in War on Drugs." Science 242 (4875): 15-16. https://science.sciencemag.org/content/242/48 75/15.2.

Hart, Carl L. 2017. "Viewing addiction as a brain disease promotes social injustice." Nature Human $\begin{array}{llll}\text { Behaviour } & 1 & \text { (3): }\end{array}$ https://www.nature.com/articles/s41562-017-0 $\underline{055}$.

Hart, Carl L. 2020. "Exaggerating harmful drug effects on the brain is killing black people." Neuron 107 (2): 215-218.

https://www.sciencedirect.com/science/article/ pii/S0896627320304736. 
Hoppe, Travis A, Aviva Litovitz, Kristine A Willis, Rebecca A Meseroll, Matthew J Perkins, B Ian Hutchins, Alison F Davis, Michael S Lauer, Hannah A Valantine, and James M Anderson. 2019. "Topic choice contributes to the lower rate of NIH awards to African-American/black scientists." Science Advances 5 (10): eaaw7238. https://advances.sciencemag.org/content/5/10/ eaaw7238.

Krane, Kris. 2019. "Bigger Than Cannabis: Lessons From The Drug Policy Alliance Biennial Conference." Forbes, December 6, 2019, 2019. https://www.forbes.com/sites/kriskrane/2019/ 12/06/recapping-the-drug-policy-alliances-annu al-conference/.

Mervis, Jeffrey. 2019. "Study identifies a key reason black scientists are less likely to receive NIH funding | Science | AAAS." Science, 2019-10-09T14:00:01-04:00, 2019. https://www.sciencemag.org/news/2019/10/st udy-identifies-key-reason-black-scientists-are-les s-likely-receive-nih-funding.

National Institute on Drug Abuse. 2016. 2016-2020 NIDA Strategic Plan | NIDA's Mission. @NIDAnews. https://www.drugabuse.gov/about-nida/strategi c-plan/nidas-mission.

National Institute on Drug Abuse. 2021a. "Adolescent Brain Cognitive Development Study I Collaborative Research on Addiction at NIH." https://www.drugabuse.gov/drug-topics/adoles cent-brain/longitudinal-study-adolescent-brain-c ognitive-development-abcd-study.

National Institute on Drug Abuse. 2021b. National Institutes of Health (NIH), National Institute on Drug Abuse (NIDA) Enhancing Health Disparities Research Related to Substance Use and Addiction: Research Gaps and Opportunities Executive Summary.

https://www.drugabuse.gov/about-nida/racial-e quity-initiative/research-gaps-opportunities.

National Institute on Drug Abuse. 2021c. Overdose Death Rates | National Institute on Drug Abuse. @NIDAnews.

https://www.drugabuse.gov/drug-topics/trendsstatistics/overdose-death-rates.

National Institute on Drug Abuse. 2021d. "Racial Equity Initiative | National Institute on Drug Abuse." @NIDAnews. Last Modified 2021-02-26. https://www.drugabuse.gov/about-nida/racial-e quity-initiative.

National Institute on Drug Abuse. 2021e. RFA: Social Determinants of Health | NIH SBIR/STTR. https://sbir.nih.gov/nida/RFA\%3ASocial_Determ inants.
National Institutes of Health. 2021. "Racial Disparities in NIH Funding | NIH." https://diversity.nih.gov/building-evidence/racia l-disparities-nih-funding.

Palepu, Anita, Steffanie A Strathdee, Robert S Hogg, Aslam H Anis, Sandra Rae, Peter GA Cornelisse, David M Patrick, Michael V O'Shaughnessy, and Martin T Schechter. 1999. "The social determinants of emergency department and hospital use by injection drug users in Canada." Journal of Urban Health $\quad 76$ (4): 409-418. https://pubmed.ncbi.nlm.nih.gov/10609591/.

Rosenberg, Alana, Allison $\mathrm{K}$ Groves, and Kim M Blankenship. 2017. "Comparing Black and White drug offenders: Implications for racial disparities in criminal justice and reentry policy and programming." Journal of drug issues 47 (1): 132-142.

https://www.ncbi.nlm.nih.gov/pmc/articles/PM C5614457/.

Shikles, JL, AB Jojokian, RM Martinez, N Donovan, JL Guilliams-Tapia, Experience Education, and United States of America. 1990. "Drug Abuse: Research on Treatment May Not Address Current Needs."

https://www.oip.gov/ncirs/virtual-library/abstr acts/drug-abuse-research-treatment-may-not-ad dress-current-needs.

Taffe, Michael A, and Nicholas W Gilpin. 2021. "Equity, Diversity and Inclusion: Racial inequity in grant funding from the US National Institutes of Health." $\quad$ Elife $\quad 10$ : 665697. https://elifesciences.org/articles/65697.

The Drug Policy Alliance. 2021a. "A Brief History of the Drug War." https://drugpolicy.org/issues/brief-history-drug -war.

The Drug Policy Alliance. 2021b. "Mass Incarceration and Criminalization."

https://drugpolicy.org/issues/mass-criminalizati on.

The Drug Policy Alliance. 2021c. "Race and the Drug War." [Website]. The Drug Policy Alliance. https://drugpolicy.org/issues/race-and-drug-wa r.

The Drug Policy Alliance. 2021d. "Supervised Consumption Services." The Drug Policy Alliance. Accessed 2021. https://drugpolicy.org/issues/supervised-consu mption-services. 
The Drug Policy Alliance. 2021e. The Drug War, Mass Incarceration and Race. The Drug Policy Alliance. https://www.unodc.org/documents/ungass2016 Contributions/Civil/DrugPolicyAlliance/DPA Fa ct Sheet Drug War Mass Incarceration and Race June2015.pdf.

Tonry, Michael. 1994. "Race and the War on Drugs." University of Chicago Legal Forum: 25. https://chicagounbound.uchicago.edu/cgi/viewc ontent.cgi?article $=1155 \&$ context $=$ uclf.

Volkow, Nora. 2021. "NIH and NIDA Work to End Structural Racism in Biomedical Science | National Institute on Drug Abuse." @NIDAnews. https://www.drugabuse.gov/about-nida/noras-b $\underline{\log / 2021 / 03 / \text { nih-nida-work-to-end-structural-ra }}$ cism-in-biomedical-science.
Volkow, Nora, George Koob, and A Thomas McLellan. 2016. "Neurobiologic advances from the brain disease model of addiction." New England Journal of Medicine 374 (4): 363-371. https://www.neim.org/doi/full/10.1056/neimra 1511480

Walker, Ingrid, and Julie Netherland. 2019. "Developing a transformative drug policy research agenda in the United States." Contemporary Drug Problems 46 (1):

3-21. https://iournals.sagepub.com/doi/10.1177/009 1450918811178.

Priyanka Bushana is a Ph.D. candidate in the Neuroscience program at Washington State University. Her research is focused on the brain oscillations which support cognitive function and their relationships with oxidative stress and sleep. She is a co-founder and the president of the Health Sciences Student Advocacy Association (HSSAA), which connects science trainees and professional students to health and science policymakers.

Emma Cook is a Ph.D. candidate in the chemistry department at the University of Virginia. Her research focuses on the development of electrocatalysts for the activation and reduction of dioxygen, which is relevant to biology energy processes and alternative energy applications. She is interested in science communication and science policy relevant to climate change and equity. She received her B.S. in chemistry from the University of North Carolina at Chapel Hill in 2019.

\section{Acknowledgements}

The authors of this memo were brought together by their work through their respective science policy organizations: the Health Sciences Student Advocacy Association (HSSAA) and The Science Policy Initiative at UVA (SPUVA). We would also like to acknowledge the support and guidance of Ilene Friedman, J.D. in completing this work. 